\title{
Global evidence of constraints and limits to human adaptation
}

\author{
Adelle Thomas $^{1,2}$ (10 $\cdot$ Emily Theokritoff ${ }^{2,3} \cdot$ Alexandra Lesnikowski $^{4} \cdot$ Diana Reckien $^{5} \cdot$ Kripa Jagannathan $^{6,7}$. \\ Roger Cremades ${ }^{8,9} \cdot$ Donovan Campbell $^{10}$. Elphin Tom Joe ${ }^{11}$. Asha Sitati ${ }^{12} \cdot$ Chandni Singh $^{13}$. \\ Alcade C. Segnon ${ }^{14,15} \cdot$ Brian Pentz $^{16}$. Justice Issah Musah-Surugu ${ }^{17}$. Cristina A. Mullin ${ }^{18} \cdot$ Katharine J. Mach $^{19}$. \\ Leah Gichuki $^{20}$. Eranga Galappaththi ${ }^{21,22} \cdot$ Vasiliki I. Chalastani $^{23} \cdot$ Idowu Ajibade $^{24} \cdot$ Raquel Ruiz-Diaz $^{25}$. \\ Caitlin Grady ${ }^{26}$. Matthias Garschagen ${ }^{27}$ • James Ford ${ }^{28} \cdot$ Kathryn Bowen ${ }^{29} \cdot$ Global Adaptation Mapping Initiative \\ Team
}

Received: 22 February 2021 / Accepted: 29 June 2021 / Published online: 26 August 2021

(C) The Author(s) 2021

\begin{abstract}
Constraints and limits to adaptation are critical to understanding the extent to which human and natural systems can successfully adapt to climate change. We conduct a systematic review of 1,682 academic studies on human adaptation responses to identify patterns in constraints and limits to adaptation for different regions, sectors, hazards, adaptation response types, and actors. Using definitions of constraints and limits provided by the Intergovernmental Panel on Climate Change (IPCC), we find that most literature identifies constraints to adaptation but that there is limited literature focused on limits to adaptation. Central and South America and Small Islands generally report greater constraints and both hard and soft limits to adaptation. Technological, infrastructural, and ecosystem-based adaptation suggest more evidence of constraints and hard limits than other types of responses. Individuals and households face economic and socio-cultural constraints which also inhibit behavioral adaptation responses and may lead to limits. Finance, governance, institutional, and policy constraints are most prevalent globally. These findings provide early signposts for boundaries of human adaptation and are of high relevance for guiding proactive adaptation financing and governance from local to global scales.
\end{abstract}

Keywords Climate change $\cdot$ Adaptation $\cdot$ Limits $\cdot$ Constraints $\cdot$ Systematic review

\section{Introduction}

Successful adaptation to the impacts of climate change is one of the defining challenges of this century (IPCC 2018). However, while natural and social systems have capacities to adapt, these capacities are neither boundless nor evenly spread (Dow et al. 2013a). Understanding constraints and limits to adaptation reinforces the need for rapid and ambitious mitigation, has important implications for anticipating and planning for impacts of climate change, and is linked to key themes in the United Nations Framework Convention on Climate Change (UNFCCC) including loss and damage, resources needed for climate action, and the global stocktake

Communicated by Wolfgang Cramer

Adelle Thomas

Adelle.thomas@gmail.com

Extended author information available on the last page of the article
(Mechler et al. 2020; Thomas et al. 2020). Research to identify patterns in how constraints and limits are experienced in different regions and sectors and by different actors is thus needed to support evidence-based approaches to these key themes.

The concept of limits to adaptation has a long history, developing along with the recognition that mitigation alone would be insufficient to curtail climate change impacts (Adger et al. 2009). Terms such as thresholds, tipping points, and regime shifts have been used to refer to the concept of climate change exceeding the capacity of adaptation efforts to avoid significant harm (Dow et al. 2013b). The Intergovernmental Panel on Climate Change (IPCC) Fifth Assessment Report (AR5) consolidated multiple conceptualizations and terms to develop an actor-centered definition of limits to adaptation - " the point at which an actor's objectives or system's needs cannot be secured from intolerable risks through adaptive action" (Klein et al. 2015, p. 907).

Limits are further classified as either soft or hard. Soft limits are those where adaptation options are currently not available but may become available in the future, while hard 
limits are those where no further adaptation is possible. Soft limits are thus mutable, have largely been associated with human systems, and are chiefly affected by a range of socioeconomic, cultural, and biophysical constraining factors that make it harder to plan and implement adaptation (Klein et al. 2015). Often, these constraints or barriers interact, resulting in soft limits that cannot be overcome at specific points in time. As detailed by Klein et al. (2015, pg. 911), "multiple constraints can significantly reduce the range of adaptation options and opportunities available to actors and therefore may pose fundamental limits to adaptation (very high confidence)".

This framing of adaptation constraints and limits has been used in subsequent IPCC Special Reports and in a largely theoretical set of literature that hypothesizes how limits to adaptation may be experienced in different contexts (Mechler et al. 2020). Relevant contributions highlight the need to consider socio-economic, historical, and environmental characteristics that influence how limits may be experienced (Filho and Nalau 2018). A variety of case studies find that limits are influenced by a broad range of constraints, including inadequate governance structures and systems (Chanza 2018; Gilfillan 2018), rigid gender and cultural norms (Greenough 2018), lack of political will (Hetz 2018), and insufficient financial resources (Ologeh et al. 2018).

The perceived ambiguity between constraints and soft limits has led some to negate the concept of mutable soft limits and instead frame these more socially constructed limits as barriers - obstacles to adaptation that are due to value systems and which can theoretically be overcome with additional resources and efforts (Eisenack et al. 2014; Hinkel et al. 2018). Biesbroek et al. (2014) differentiate between an "optimist" analytical lens of viewing barriers as problems that can be overcome by optimizing actors and processes and a "pessimist" lens where barriers are understood to be systemic, unmanageable, and with little possibility of being avoided or removed. The pessimist lens acknowledges soft limits to adaptation, recognizing that the difficulty of overcoming barriers may lead to limits in the ability of adaptation to reduce risks at a certain point in time, despite the social factors that lead to such a limit. The optimist lens frames barriers as distinct from limits - which are understood as absolute and unsurpassable - thus obscuring that soft limits also have the potential to be absolute at a specific point in time. However, among studies with an optimist lens, there is increasing recognition that while barriers may be surmountable in theory, in practicality this may be highly unlikely, thus providing further support for acknowledging soft limits (Barnett and Palutikof 2014; Barnett et al. 2015). Similarly, thresholds and tipping points often leading to limits have also been described in qualitative literature as "transformation tipping points," where more desirable states can be reached than the current ones through changes in strategy, behavior, idea, or technology (Van Ginkel et al. 2020).
As of yet, there is no global synthesis and assessment of documented limits to adaptation, despite the rapidly growing empirical scholarship on implemented adaptation (BerrangFord et al. n.d.). This growing literature offers a rich resource base to analyze and quantitatively synthesize how constraints and limits are currently being faced and framed. Here, we document insights on constraints and limits to adaptation using a systematic review of 1,682 scientific articles focused on adaptation responses implemented across the globe. We follow the IPCC framing, as detailed in Box 1, to differentiate between constraints, soft limits, and hard limits, calling attention to the importance of defining these concepts often mixed in the literature. We use the geographic and sectoral categories that have been defined for the IPCC Sixth Assessment Report, as further detailed in the "Methods" section.

We draw from this empirical literature to assess the evidence on constraints and limits for different regions, sectors, hazards, adaptation response types, and actors. We also assess the methodologies used to identify limits to adaptation. This analysis responds to calls for empirical research that synthesizes dispersed knowledge on constraints and limits, enabling policy, research, and practitioner communities to identify common patterns (Eisenack et al. 2014).

\section{Methods}

A systematic review was used to analyze the academic literature on constraints and limits to adaptation. Systematic literature reviews are widely used to synthesize large numbers of studies in a standard and transparent manner (Singh et al. 2017) and allow quantitative and qualitative analyses (Sud et al. 2015). For climate change adaptation in particular, systematic reviews are an innovative methodology that enable mapping and tracking of the rapidly expanding research literature (Berrang-Ford et al. 2015). They have been used as a methodology to assess a broad range of adaptation foci (Owen 2020; Robinson 2020). Rapidly growing volumes of research literature can also benefit from new technology developments such as machine learning which provides solutions for vast bodies of literature by facilitating systematic mapping and increasing the efficiency of evidence synthesis (Lamb et al. 2019; Callaghan et al. 2020; Haddaway et al. 2020).

\section{Phase 1: Global Adaptation Mapping Initiative}

This paper draws on data from the Global Adaptation Mapping Initiative (GAMI), the largest systematic review to date on climate change adaptation literature (Berrang-Ford et al. n.d.). The overall aim of GAMI is to investigate how humans are adapting to climate change on a global scale and the scope, nature, and progress of this adaptation. Key procedures involved in the systematic review are summarized 
Box 1 Adaptation constraints and limits

IPCC AR5 and subsequent Special Reports use the following framing of adaptation limits and constraints (Mechler et al. 2020).

Adaptation limit: The point at which an actor's objectives or system needs cannot be secured from intolerable risks through adaptive actions.

Soft limit: Options are currently not available to avoid intolerable risks through adaptive action.

Hard limit: No adaptive actions are possible to avoid intolerable risks.

Adaptation constraint - factors that make it harder to plan and implement adaptation actions; also referred to as obstacles or barriers. These are further categorized as:

\begin{tabular}{|c|c|}
\hline Category of Constraint & Description \\
\hline Economic & existing livelihoods, economic structures, and economic mobility \\
\hline Social/cultural & $\begin{array}{l}\text { social norms, identity, place attachment, beliefs, worldviews, values, } \\
\text { awareness, education, social justice, and social support }\end{array}$ \\
\hline Human capacity & $\begin{array}{l}\text { individual, organizational, and societal capabilities to set and achieve } \\
\text { adaptation objectives over time including training, education, and skill } \\
\text { development }\end{array}$ \\
\hline $\begin{array}{l}\text { Governance/Institutions/ } \\
\text { Policy }\end{array}$ & $\begin{array}{l}\text { existing laws, regulations, procedural requirements, governance scope, } \\
\text { effectiveness, institutional arrangements, adaptive capacity, and absorption } \\
\text { capacity }\end{array}$ \\
\hline Financial & lack of financial resources \\
\hline $\begin{array}{l}\text { Information/Awareness/ } \\
\text { Technology }\end{array}$ & lack of awareness or access to information or technology \\
\hline Physical & presence of physical barriers \\
\hline Biological & $\begin{array}{l}\text { temperature, precipitation, salinity, acidity, and intensity and frequency of } \\
\text { extreme events including storms, drought, and wind }\end{array}$ \\
\hline
\end{tabular}

below, and Berrang-Ford et al. (2020) provides further details of the GAMI methodology.

This systematic review used the Population, Interest, Context, Scope, and Time (PICoST) approach, which were defined to set the boundaries of the review (see Table 1). GAMI consisted of three main stages, screening, coding, and synthesis, described in the following sections.

\section{Screening}

Articles meeting the PICoST criteria were included in the overall data set. Search terms were identified through keywords from ten representative adaptation publications.
Search strings were then constructed for the three search engines used to extract relevant literature (Web of Science, Scopus, and MEDLINE). Climate change and adaptation/adaptation-related responses were the two main concepts used to build these queries. Search terms such as resilience and risk management were also included to capture the breadth of climate adaptation literature. The search strings were restricted to articles referencing climate change or global warming in their titles, abstracts, or keywords. Articles referring to weather, environmental variability, or meteorological variables without explicit reference to climate change were excluded. Any language was eligible as long as the article was indexed in English. 
Table 1 Scope of the systematic review using the Population, Interest, Context, Scope, and Time (PICoST) approach

\begin{tabular}{|c|c|}
\hline $\begin{array}{l}\text { PICoST } \\
\text { component }\end{array}$ & As defined in the review \\
\hline Population (P) & $\begin{array}{l}\text { Global population encompassing all human societies and ecosystems of importance to } \\
\text { humans that are impacted by climate change }\end{array}$ \\
\hline Interest (I) & $\begin{array}{l}\text { Autonomous and planned human adaptation-related responses to climate change, including } \\
\text { human-assisted adaptation in natural systems. Excluded evolutionary or autonomous } \\
\text { adaptation in natural systems }\end{array}$ \\
\hline Context (C) & $\begin{array}{l}\text { Any empirically documented adaptation-related responses taken in response to observed or } \\
\text { projected climate change risk. The term "adaptation-related responses" was used because } \\
\text { some responses may be maladaptive or ineffective and not achieve adaptive outcomes }\end{array}$ \\
\hline Scope $(S)$ & Empirical peer-reviewed literature (gray literature excluded) \\
\hline Time $(\mathrm{T})$ & $\begin{array}{l}\text { Scientific literature published between } 2013 \text { and } 2020 \text { (capturing literature published from } \\
\text { IPCC Assessment Report } 5 \text { onwards) }\end{array}$ \\
\hline
\end{tabular}

These search strings resulted in a total of 48,816 articles once the duplicates had been removed. A combination of manual review and machine learning was then used to screen the articles according to the PICoST criteria. A machine learning classifier was then developed and trained to detect papers that met the GAMI inclusion criteria based on their titles and abstracts. A training dataset was created by randomly sampling and manually screening titles and abstracts for 4,500 of the 48,816 documents. This taught the machine learning algorithm how to recognize documents to be included for the further 44,316 documents that were then screened via machine learning. This process built the final list of 2,032 articles to be reviewed in the coding phase. Fischer et al. (2020) provide further detail on this screening process.

\section{Coding}

Following the screening of titles and abstracts, the 2,032 resulting articles were coded. Three hundred fifty of these articles were manually excluded during the coding process due to insufficient data for analysis or the article not being substantially empirical. The coding process was undertaken in SysRev, an online document review platform used for data extraction. Based on the categorizations used by the IPCC in Working Group II for the Sixth Assessment Report, the GAMI dataset was divided into 13 regional and sectoral thematic groups. The regions were defined as Africa, Asia, Australasia, Central and South America, North America, Europe, and Small Islands States. The sectors were terrestrial and freshwater ecosystems; ocean and coastal ecosystems; water quality and sanitation; food, fiber, and other ecosystem products; cities, settlements, and key infrastructure; health, well-being, and communities; and poverty, livelihoods, and sustainable development. Coders were assigned to at least one of these specific groups.

Before starting the coding process, coders were given a codebook with background information and detailed instructions. The questions were structured into seven sections: (1) general information; (2) who is responding; (3) what responses are documented; (4) what is the extent of adaptation-related responses; (5) are responses reducing risks; (6) adaptation limits; and (7) assessing confidence in evidence (see Table 2). The questions included closed questions with restricted options, open questions, and open fields where coders were asked to include quotes supporting their answers. Two additional screening questions were answered when coding: (1) is the document relevant based on the inclusion criteria? and (2) does the document have sufficient information to code (defined as a minimum of half a page of content on adaptation-related responses)? The first question allowed coders to double-check all articles which were considered relevant by the algorithm and the second excluded documents with insufficient documentation in the main text of the article. Each article was double-coded to ensure adequate quality of coding. Articles categorized in multiple thematic groups were coded by four or more coders. This process resulted in 1,682 coded articles in the final GAMI database, with 5,383 unique sets of code. Lesnikowski et al. (2020) provide further detail on this coding process.

\section{Synthesis}

Since articles were at minimum double-coded, reconciliation of differing codes had to be undertaken. This was done in the R statistical environment (R Team 2019) with a series of if/ then statements. The code and rationale are available on an open source platform (Siders 2020). The final GAMI database was then compiled into an Excel file with one article per row and 70 columns (one column per coded question).

\section{Phase 2: Focused assessment of constraints and limits}

This GAMI database was then used for a focused assessment of constraints and limits to adaptation. Qualitative information 
Table 2 Research themes and questions

Research theme

1. General

2. Who is responding?

3. What responses are documented?

4. What is the extent of the adaptation-related responses?

5. Are adaptation-related responses reducing risk?

6. Adaptation limits

7. Assessing confidence in evidence
Specific questions

1.1. Description of topic summarized in document (open field)

1.2. Region(s) or geographic focus of adaptive responses documented (restricted options)

1.3. Open field to specify region

1.4. Sectoral focus of adaptive responses documented (restricted options)

1.5. Cross-cutting themes (restricted options)

1.6. Consideration of local knowledge (restricted options)

1.7. Consideration of Indigenous knowledge (restricted options)

2.1. Who is engaging in adaptation responses? (restricted options)

2.2. Open field if answered 'other' to above question

2.3. Is there evidence that particular vulnerable groups are targeted in adaptation responses? (restricted options)

2.4. Open field if answered 'other' to above question

3.1. What types of responses are reported? (restricted options)

3.2. What types of implementation tools are reported? (open field)

3.3. What climatic hazards are being responded to? (restricted options)

3.4. Open field if answered 'other' to above question

3.5. What aspects of exposure or vulnerability are targeted by adaptation responses? (restricted options)

3.6. Open field if answered 'other' to above question

3.7. What is the stated (or implied/assumed) link to reduction in risk? (open field)

4.1. What is the general stage of response activities? (restricted options)

4.2. Is there any information on who financed the response? (restricted options)

4.3. Is there any information on the costs of adaptation? (restricted options)

4.4. What is the depth of response activities? (open field)

4.5. What is the scope of response activities? (open field)

4.6. What is the speed of response activities? (open field)

5.1. Is there any evidence that activities successfully reduced risk? (restricted options)

5.2. Open field if 'yes' to the above question.

5.3. Are indicators or measures of 'success' identified? (restricted options)

5.4. Open field if 'yes' to the above question.

5.5. Is there any consideration of risks or maladaptation associated with the adaptation responses? (open field)

5.6. Is there any reference to co-benefits? (open field)

6.1. Are limits to adaptation described (using the IPCC definition of limits)? (restricted options)

6.2. Open field if 'yes' to the above'.

6.3. Are these hard or soft limits? (open field)

6.4. Is there evidence to indicate whether responses approach, challenge, or exceed soft limits? (open field)

7.1. Are there any major methodological limitations? (open field)

7.2. Did the document provide sufficient information to answer all of these coding questions? (coherence) (open field)

7.3. Comment on the quantity and quality of data upon which the findings are based (adequacy) (open field)

7.4. Are the results relevant to a particular context only? (relevance) (open field) from phase 1 , namely the coded information from the research themes 1, 2, 3, and 6 (see Table 2), was the data used for this study. From the 1,682 papers of the GAMI database, 1,362 were coded as containing information on constraints and/or limits. For phase 2, information coded under research theme 6 on adaptation limits went through an additional round of review. This allowed us to confirm the mention of constraints and/or limits and to determine a relevance score indicating to what extent constraints and/or limits were discussed, based on the criteria outlined below.
A relevance score of 1 was assigned to papers discussing constraints, barriers, or impediments to adaptation but not relating these issues to soft or hard limits. Although some articles used the words "limit" or "limitation," these terms were not used to refer to soft or hard limits, as defined in Box 1, but corresponded to constraints. A relevance score of 2 was assigned to papers that linked constraints, barriers, or impediments to soft or hard limits. Terms such as "threshold," "tipping point," or "barrier" may have been used instead of "limit," but their description aligned with our definition of limits to 


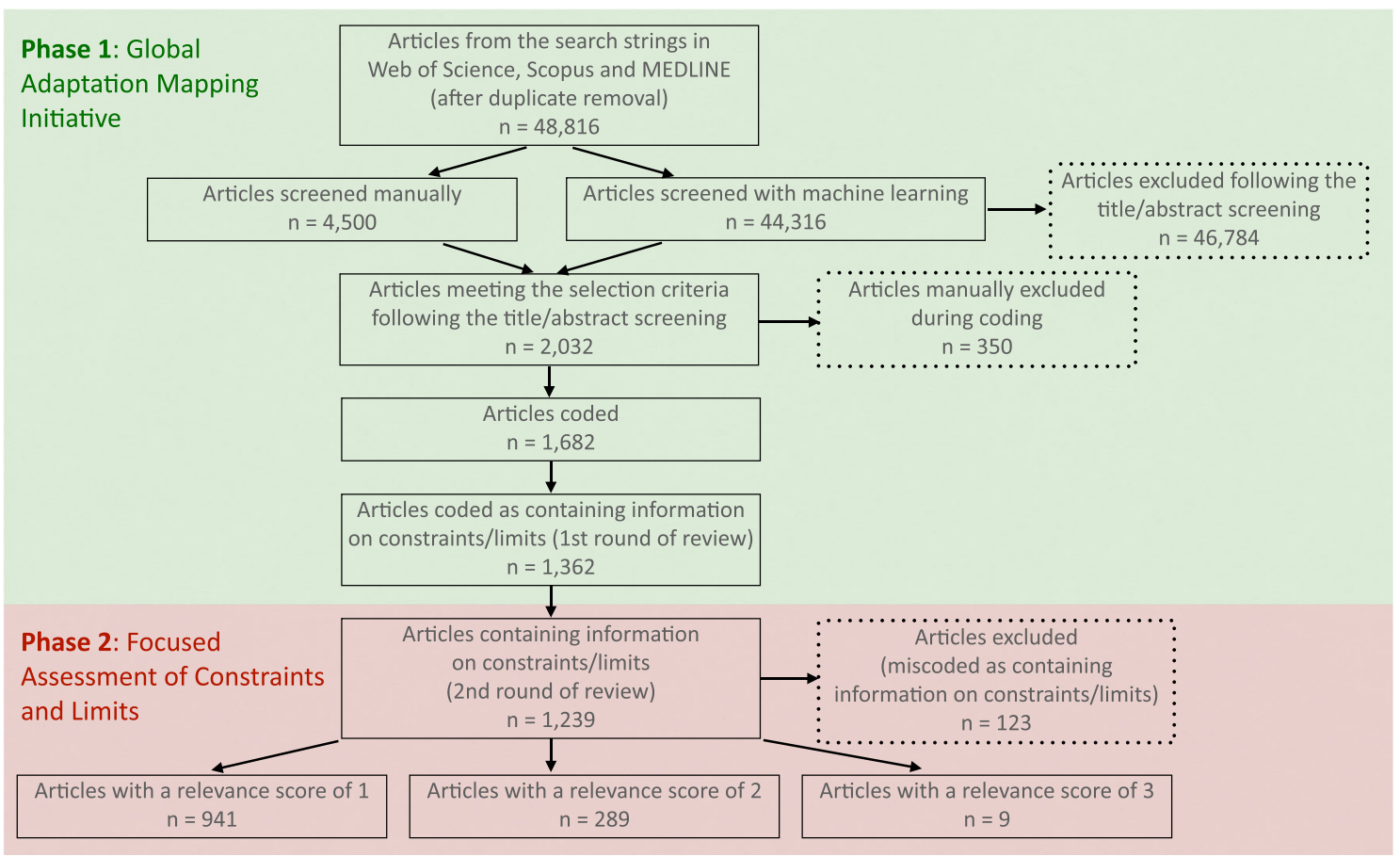

Fig 1 Systematic review diagram

adaptation. Limits to adaptation were discussed in a general sense, with no discussion on levels of socio-economic or environmental change that may be associated with reaching a limit. A relevance score of 3 was assigned to papers that engaged most directly with limits to adaptation. Different terminologies may have been used but were aligned with our definitions of soft and hard limits. These papers provided detailed information on limits, including some discussion of socio-economic or environmental change that may lead to limits.

This second round of review identified 123 papers that were miscoded in phase 1 as containing information on limits or constraints to adaptation. In many instances, papers contained information on limitations of the study or methodology used but not on limits or constraints to adaptation. One limitation of the coding process is that although coders assessed how adaptation responses were affecting risk, they did not separately identify whether risks were described as intolerable or tolerable. Having this information separately coded would have provided additional information that would support the assignment of relevance scores.

A total of 1,239 papers were thus assigned a relevance score with the vast majority $(941,76 \%)$ having a relevance score of 1 , a minority $(289,23 \%)$ with a relevance score of 2 , and very few $(9,1 \%)$ with a relevance score of 3 . The constraints from these 1,239 papers were then classified into the eight categories that are detailed in Box 1. We also assessed whether the identified constraints were described as able to be overcome and thus related to soft limits, not able to be overcome and thus related to hard limits or a mixture of constraints that may be overcome or not overcome thus related to both soft and hard limits.

The data from all 1,239 papers was used for the analysis of the regional and sectoral variance of the evidence base of constraints and limits. In addition, the links between different adaptation response types, hazards, and actors facing constraints and limits were also studied. For this, the information coded under the research themes 1,2 , and 3 were considered (see Table 2).

Using the COUNTIF function from Excel, counts were undertaken and cross-tab tables were produced with the different categories of constraints, types of limits, and response types/hazards/actors. These counts were further categorized by sector and region. Percentages were then calculated based on the total amount of documents for a specific association. For example, the percentage of literature discussing ecosystem-based adaptation efforts and mentioning financial constraints was calculated. Bonferroni-corrected chi-square tests for independence were conducted in the $\mathrm{R}$ statistical environment ( $\mathrm{R}$ Team 2019) to identify statistically significant associations. Significance levels between the eight constraint types and the various categories of (i) adaptation responses, (ii) hazards, and (iii) actors were tested. In addition, the significance levels between relevance scores (1, 2 , and 3 ) and the various categories of (i) adaptation responses, (ii) hazards, and (iii) actors were also tested. The same tests were performed for the information on soft/hard/both limits (from question 6.3, see Table 2). pvalues $(\%)$ were calculated using the chisq.test function. 
Uncorrected chi-square test results are available in the Supplemental Materials.

For our assessment of methods used to identify limits ("Methodologies used to identify limits" section), all the original articles for the papers with a relevance score of 3 were reviewed. GAMI (2021) has the full bibliographic list of all 1,682 publications that were coded and assessed. For this paper, we reference specific articles to illustrate our findings.

\section{Results}

\section{Regional and sectoral variance in evidence base on constraints and limits}

Our analysis of 1,682 papers reporting on adaptation action to date shows that while constraints feature very prominently in current adaptation, information on limits is scarce and tends to be more conceptual than analytical. Using the IPCC definitions of constraints and limits, we found that the majority of the papers assessed $(1,239,74 \%)$ contained information on either constraints or limits. Of these 1,239 papers, most $(76 \%)$ discussed constraints to adaptation but did not directly relate these constraints to limits being reached at some point. Roughly one in four papers (23\%) went a step further and linked constraints as leading to limits but discussed limits in a general sense, without identifying levels of socio-economic or environmental change that may be associated with limits. Only $1 \%$ of the papers provided the most detailed information about soft or hard limits, including insights on thresholds of socio-economic or environmental change that may result in limits being reached.

There are also regional differences in identification of constraints and limits. Compared to the overall number of papers on adaptation responses, Australasia (58\%) and Europe (62\%) had lower percentages of papers that contained information on constraints or limits while Small Islands (79\%), Asia (78\%), Africa (77\%), and Central and South America (75\%) had higher percentages of papers with information on these topics (Figure 3).

Constraints related to soft limits were more prevalent than constraints related to hard limits. Seventy-eight percent of papers referred to constraints that could be overcome and may thus be related to soft limits, $21 \%$ contained information on constraints that may lead to both soft and hard limits, and $1 \%$ identified constraints that could not be overcome and thus related to hard limits only. Central and South America (30\%) and Small Islands (29\%) have higher than average percentages of papers that identify constraints that may lead to both soft and hard limits, in contrast to other regions where soft limits are dominant (Figure 2). In combination with the previous finding, this suggests that Central and South America and Small Islands in particular are facing challenges to adaptation that may not be surmountable, leading to both soft and hard limits.

Reported adaptation constraints and limits are mostly crosssectoral - more than half $(63 \%)$ of the studies classify adaptation actions as being related to two or more sectors. There are regional differences in these patterns of sectoral overlap, with $44 \%$ of Small Islands papers identifying three or more sectors compared to $56 \%$ of Australasia papers identifying only one sector,

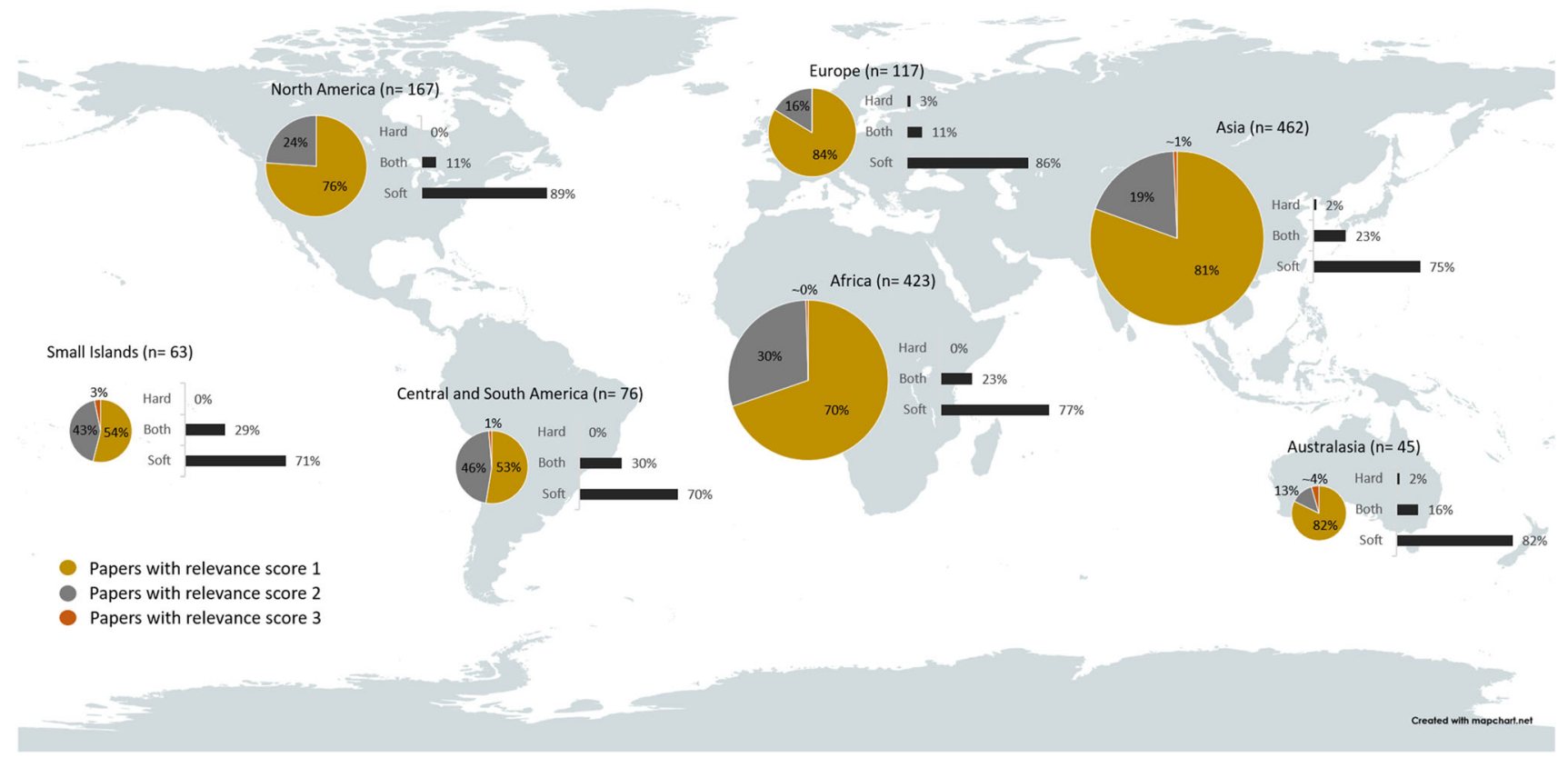

Fig 2 Map of literature on constraints and limits to adaptation by region. Relevance score of 1 - the assessed paper discussed constraints to adaptation but did not link these constraints to limits. Relevance score of 2 - the paper linked constraints to limits and discussed limits in a general sense. Relevance score of 3-the paper provided detailed information on limits with discussion of levels of socio-economic or environmental change that would lead to limits being reached. Size of pie charts is proportional to the number of papers. 
Fig 3 Number of adaptation papers that contained information on constraints or limits by region

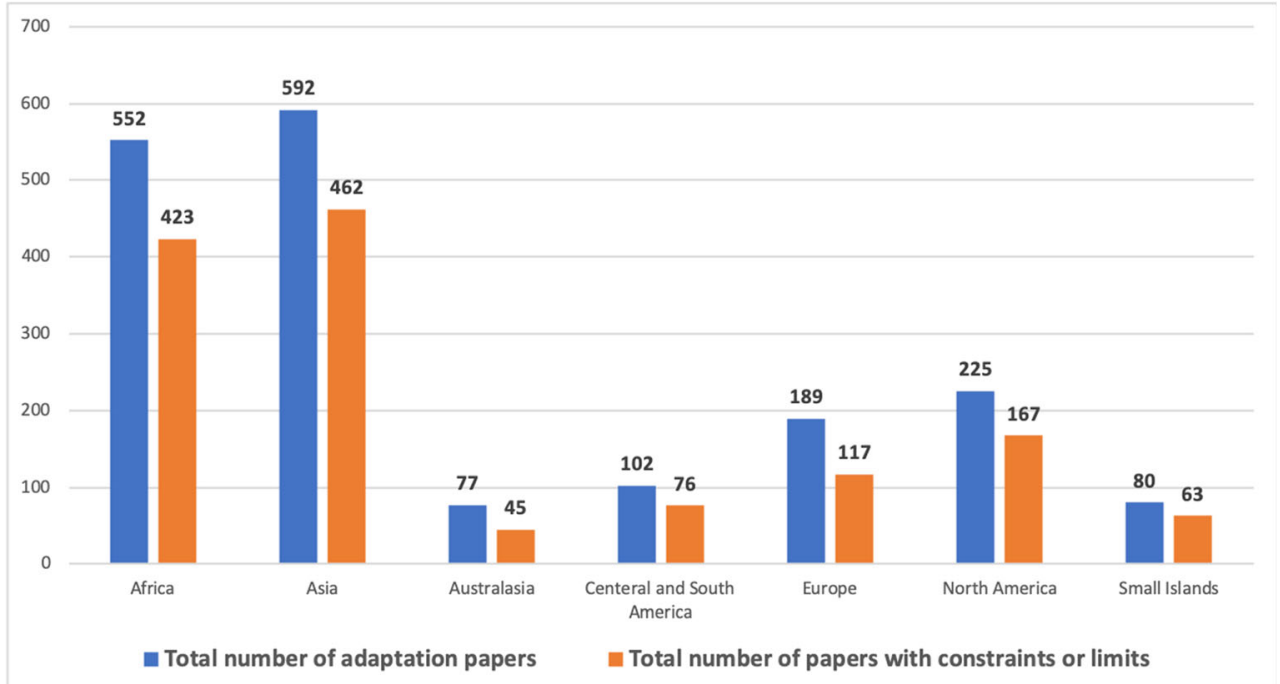

suggesting that adaptation constraints and limits may have widespread effects in Small Islands in particular, affecting a range of sectors.

Food, fiber, and other ecosystem products (66\%) and poverty and livelihoods and sustainable development (48\%) emerge as the sectors with the largest share of papers on constraints and limits (Figure 4). However, while papers on ocean and coastal ecosystems only make up $11 \%$ of the total number of papers, this sector has the highest percentage of papers that link constraints to limits. This supports findings that adaptation to changes in the ocean and cryosphere is particularly challenging and already face limits (IPCC 2019). Regional differences in sectoral concentrations highlight sectors where adaptation is particularly facing constraints or limits. Most papers in Australasia (58\%) and Small Islands (59\%) focus on health, well-being, and communities, while in Europe, cities, settlements, and key infrastructure (44\%) have the highest percentage of papers documenting constraints or limits.

Previous research highlights that a range of constraints affect adaptation (Shackleton et al. 2015; Gawith and Hodge 2018). Our findings support this, with the majority of papers $(81 \%)$ identifying more than one constraint. However, there are regional differences in the number of constraints identified per paper. Small Islands have the largest percentage of four or more constraints identified per paper (32\%), while Europe leads in the majority of papers $(43 \%)$ that acknowledge only one constraint (Figure 5). Small Islands emerge as a specific region where soft limits may arise and be more difficult to overcome given the high number of identified constraints.

\section{Constraints and limits for different adaptation response types}

Constraints to adaptation vary by the type of adaptation response. Figure 6 shows that adaptation responses are linked to an array of different types of constraints. However, only some of these connections are statistically significant. Behavioral and cultural adaptation responses are highly associated with economic and socio-cultural constraints $(\mathrm{p} \leq 0.01)$, suggesting that these responses may be challenged by existing social structures and that more transformational approaches to adaptation may be needed (Pelling et al. 2015; van Valkengoed and Steg 2019). Ecosystem-based responses are significantly associated with physical constraints (for example geographical features such as rivers or coastlines) $(\mathrm{p} \leq 0.05)$, indicating that the appropriateness of these adaptation responses is highly place-based (Nalau et al. 2018). We also observe that institutional responses are strongly associated with governance, institutional, and policy constraints $(\mathrm{p} \leq 0.01)$ and with information, awareness, and technological constraints $(p \leq 0.05)$. This builds on case-study findings that institutional adaptation is often constrained by inadequate and mismatched human resource and technical capacities (Azhoni et al. 2017). Finally, we find that technological and infrastructural adaptation responses are strongly associated with information, awareness, and technology constraints $(\mathrm{p} \leq 0.01)$, as well as with financial constraints $(\mathrm{p} \leq 0.05)$.

Bonferroni-corrected chi-square tests of independence indicate highly significant relationships between articles that describe constraints related to both soft and hard limits and ecosystem-based, technological, and infrastructural responses $(\mathrm{p} \leq 0.01)$. A statistically significant relationship is also observed between technological and infrastructural responses and articles that specifically identify limits $(\mathrm{p} \leq$ 0.05). This suggests that ecosystem-based, technological, and infrastructural responses face constraints that may lead to limits and provides support to generalize findings from case studies that identify the limitations of these responses (Hinkel et al. 2018; Seddon et al. 2020). 
Fig 4 Percentage of articles by sector. Radar axes reflect the percentage of articles mentioning each sector over the total number of articles. Totals sum more than $100 \%$ since many papers identify more than one sector.

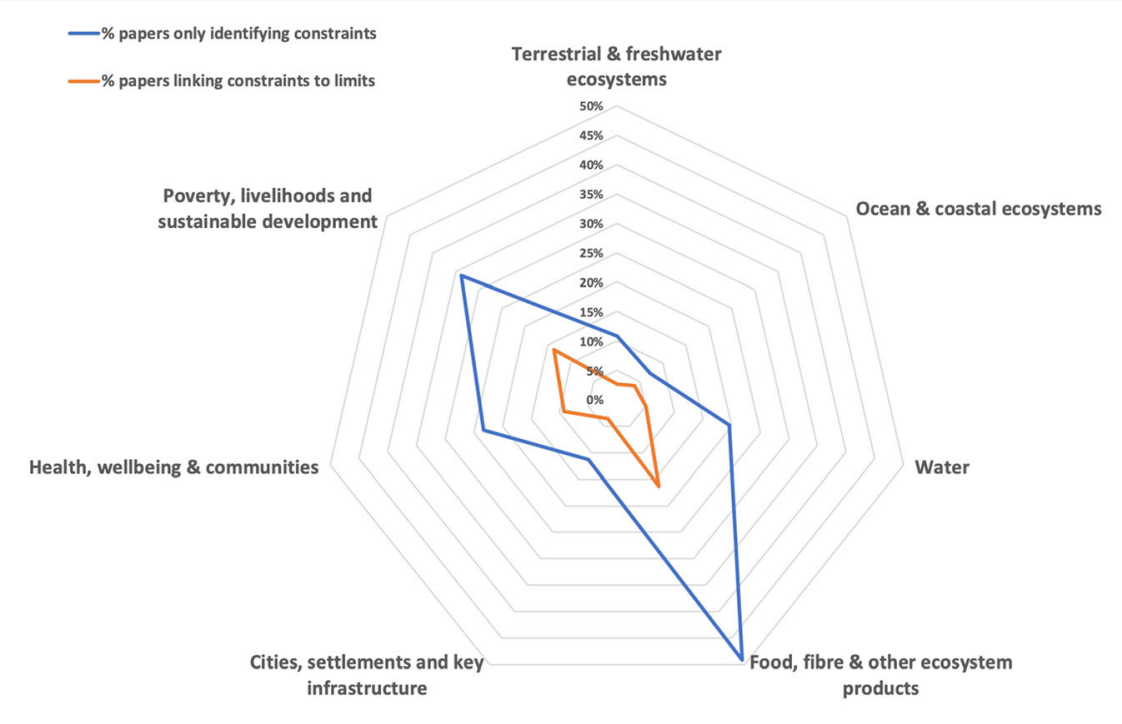

\section{Constraints and limits for adaptation to different hazards}

Across all hazard types, most articles (71-81\%) described constraints that may be overcome and thus related to soft limits, and about one-quarter reported constraints that may lead to both hard and soft limits (Figure 6). These trends were also examined regionally and sectorally, which yielded similar patterns to the global results (see Supplementary Materials). A significant association is found between constraints related to both soft and hard limits and responses to both precipitation variability and drought $(p \leq 0.05)$. Articles on precipitation variability are also likely to identify limits $(p \leq 0.05)$. Our findings suggest that many adaptation responses to all types of hazards face challenges that could be overcome with additional support, but that constraints affecting responses for precipitation variability in particular may be more difficult to address.

Although not statistically significant ( $p>0.10)$, articles on ocean temperatures and acidification and loss of arctic sea ice have the highest share of discussion on limits (36\% and 35\%, respectively), reflecting growing pressures on coral reefs and rapid environmental change in the Arctic (IPCC 2019). Conversely, articles on sea level rise have the lowest share of discussion about limits (21\%).

Bonferroni-corrected chi-square tests of independence between hazards and constraints yielded general low statistical significances, but we do observe a highly significant relationship between precipitation variability and biological constraints $(\mathrm{p} \leq 0.01)$. Along with our previous finding that articles concerned with responses to precipitation variability often identify limits, this provides strong evidence for the possibility that responses to this hazard face significant challenges that may lead to hard limits. Finally, we also find a significant relationship between responses to increased frequency and intensity of extreme heat and information, awareness, and technological constraints $(\mathrm{p} \leq 0.05)$.

\section{Constraints and limits for different actors}

Articles overwhelmingly report that individuals and households face either constraints or limits to adaptation ( $86 \%$ of articles), while fewer papers emphasize either constraints or limits experienced by local governments $(38 \%)$ and national governments (33\%). All types of actors primarily face constraints that may lead to soft limits (73-85\% articles), while some also face constraints that may lead to both soft and hard limits (17-27\% articles). Bonferroni-corrected chi-square tests indicate a strong correlation between constraints related to both soft and hard limits and individuals and households $(\mathrm{p} \leq 0.05)$ (Figure 3). We also find a highly significant association between civil society at the sub-national or local scale and literature that identifies limits $(\mathrm{p} \leq 0.01)$. This suggests that actors at smaller spatial scales face greater challenges in addressing constraints, which may lead to limits to adaptation.

The most reported constraints across all actor categories are governance, institutional, and policy (54\% on average, across all regions and sectors) and finance (49\% on average, across all sectors and regions, except Europe). Physical (13\%) and biological (10\%) constraints were least reported across actors. In particular, our analysis indicates that finance, governance, institutional, and policy constraints are key challenges for government and civil society. We find highly significant relationships between governance, institutional, and policy constraints and all government levels (national, sub-national and 
Fig 5 Number of constraints per paper by region

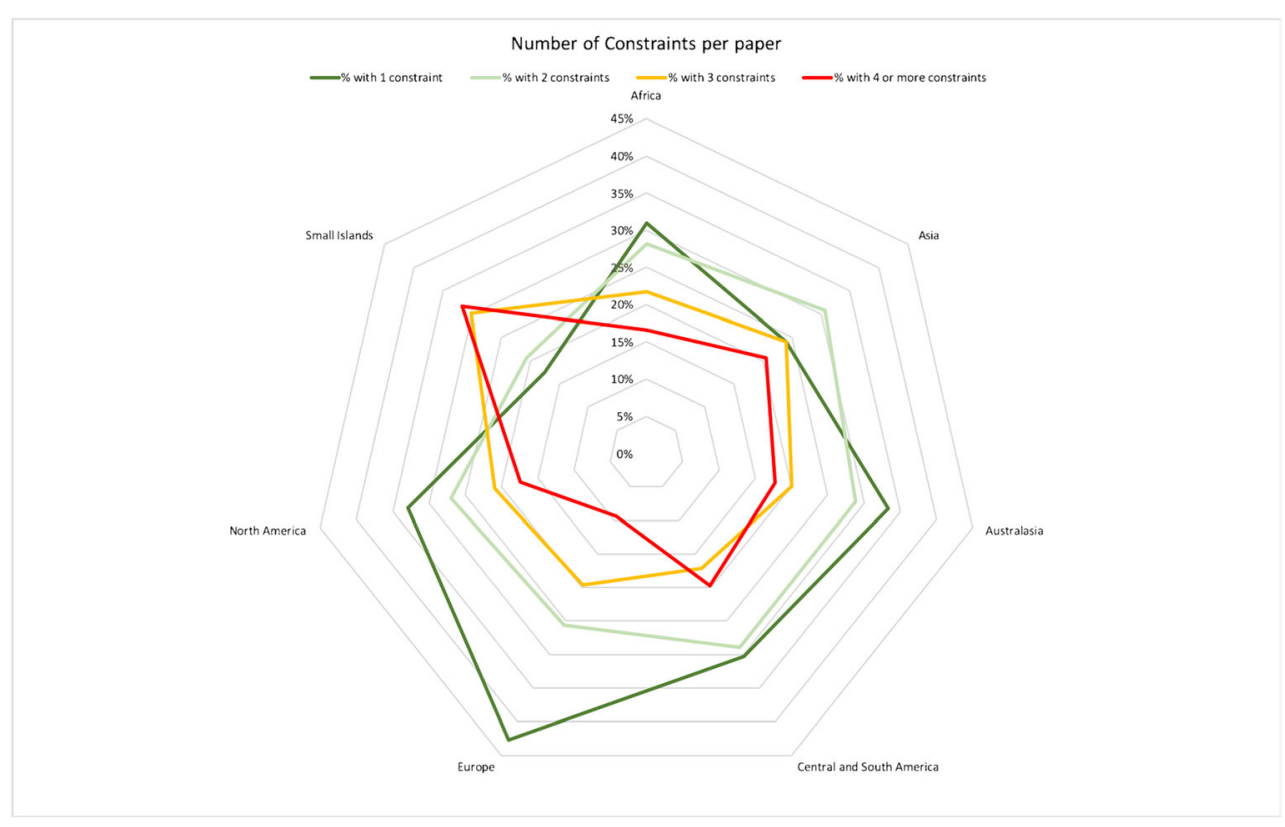

local) and civil society at the sub-national or local scale ( $\mathrm{p} \leq$ 0.01 ). A correlation is also found between governance, institutional, and policy constraints and civil society at international, multinational, and national scales ( $\mathrm{p} \leq 0.05)$. Finally, both economic and socio-cultural constraints are highly associated with individuals and households $(\mathrm{p} \leq 0.01)$, which is consistent with our previous finding that these same constraints are common with behavioral and cultural adaptation responses.

\section{Methodologies used to identify limits}

Our in-depth review of the papers that offered the most detailed information on limits to adaptation identifies methods used to assess limits. These studies relied on surveys, interviews, focus groups, and case study syntheses (Karlsson and Hovelsrud 2015; Pasaribu and Sudiyanto 2016; Warner 2016; Egbinola et al. 2017; Karapinar and Özertan 2020). The actorcentric emphasis of these methodologies shows how social conditions and governance systems enable or limit adaptation (Harvey et al. 2014; Warner 2016; Karapinar and Özertan 2020). While these articles engage most directly with limits to adaptation, we find that discussion of socio-economic or environmental thresholds for reaching limits to adaptation is largely qualitative with little quantitative assessments of particular levels of change.

\section{Discussion and conclusion}

Understanding constraints and limits to adaptation is key to evaluating the extent to which human and natural systems can adapt to climate change. Our systematic review of over 1,600 peer-reviewed articles on implemented adaptation reveals that while constraints to adaptation are widely acknowledged in the literature, slightly less than a quarter of articles link constraints to limits being reached at some point and there is a paucity of studies that provide detailed information on how limits may be experienced and when. We also find that roughly one in four studies discussing limits identify hard limitswhere no further adaptation actions would be possible. When assessing this information from different perspectives, we find important patterns and nuances including geographical differences, the need to overcome a wide spectrum of constraints, and specific challenges at the local scale.

In Small Islands, Asia, Africa, and Central and South America, a higher share of studies identify constraints and both hard and soft limits to adaptation, supporting findings from a range of perspectives that adaptation faces more challenges in developing world contexts (Millner and Dietz 2011; Bhave et al. 2016). Central and South America and Small Islands emerge as regions where there is strong evidence of both soft and hard limits, particularly for adaptation responses taken by small-scale farmers (Harvey et al. 2014; Warner 2016; Acevedo-Osorio et al. 2017; Gerlicz et al. 2019; Jezeer et al. 2019). Adaptation in Small Islands in particular face limits resulting from interactions between numerous constraints potentially affecting multiple sectors, due to the crosssectoral nature of adaptation in these regions (Robinson 2018; Otoara Ha'apio et al. 2018; Thomas et al. 2019).

Ecosystem-based, technological, and infrastructural adaptation responses are already identified as facing both soft and hard limits (Pritchard and Thielemans 2014; Jacobi 2016; Partey et al. 2018; Sandholz et al. 2018). This is a critical finding as the combination of these responses is often viewed as a "silver bullet" to prevent the most severe impacts of climate change, particularly from flooding and sea level rise 


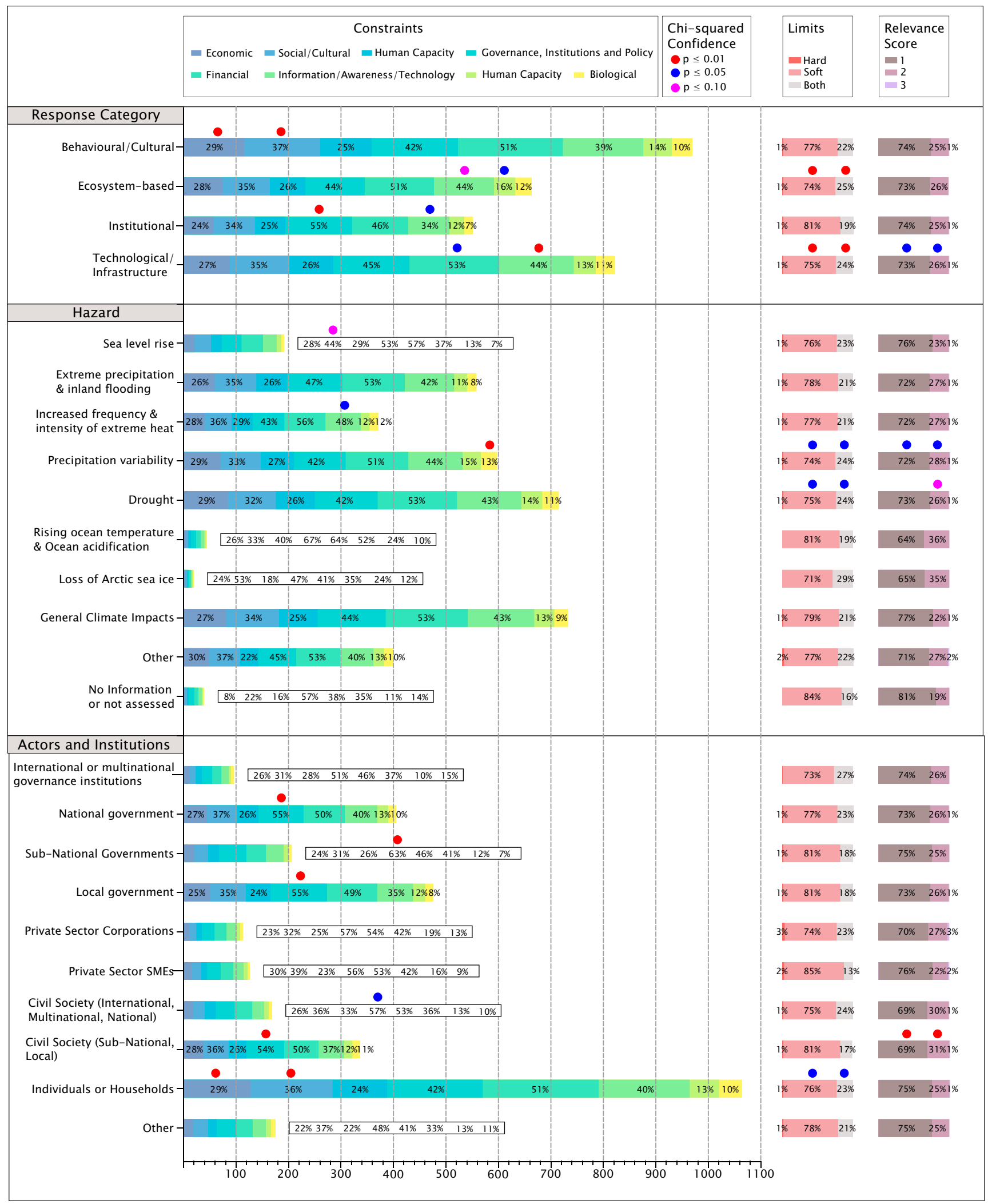

Fig 6 Constraints and limits for different adaptation responses, hazards, and actors 
(Vojinovic et al. 2016; Du et al. 2020). While the link between other adaptation response types and limits is less pronounced, we find that numerous constraints are associated to different responses types. This suggests that a range of constraints must be overcome to implement the mix of adaptation response types that are needed to reduce risk.

Individuals and civil society at local scales show greater evidence of already experiencing both soft and hard limits, resulting in increasing loss of income and assets and eroding adaptive capacity (Bauer 2013; Ferdous et al. 2019; Ahmed et al. 2019). This highlights that these actors are not likely to curtail all climate-related risks and that the involvement of the private sector and actors responsible for adaptation at national, regional, and international levels is needed. This also supports studies that find that non-governmental adaptation actions at the individual, household, and community scale may reduce some risk, but that these efforts are unable to prevent all climaterelated impacts (Bowen and Ebi 2015; Jamero et al. 2018). These are key insights for households and communities with limited resources and show the importance of coordination and support between multiple actors at different scales. However, such coordinated action faces financial, governance, institutional, and policy constraints, highlighting inadequate institutional capacities in the face of limits to adaptation, and supporting calls for bridging the adaptation finance gap (Olhoff et al. 2015). In low- and middle-income countries where adaptation is still in its early stages, soft limits may not be easily overcome if daunting financial, governance, and capacity constraints are not addressed (McNamara et al. 2017).

There are a number of priority areas for further research on limits to adaptation. Given the existing epistemological ambiguity of constraints and soft limits, clearer identification of soft limits in studies would illuminate impacts that current adaptation is unable to prevent and underscore where resources and efforts are needed to overcome constraints. Transdisciplinary assessments of adaptation limits, including the use of climate scenario projections, could provide useful insights into adapting to multiple drivers of change and provide quantitative assessments of thresholds of change associated with limits for different adaptation measures. Global assessments of the cross-border dynamics of constraints and limits to adaptation such as the interactions of climate risks with trade, finance, and migration offer meaningful entry points.

Supplementary Information The online version contains supplementary material available at https://doi.org/10.1007/s10113-021-01808-9.

Author contribution Thomas A. led and designed the structure of the paper. Thomas A., Lesnikowski A., Theokritoff E., and Jagannathan K. conceived and designed the experiments. Lesnikowski A., Theokritoff E., Jagannathan K., Segnon A., Galappaththi E., and Vasiliki I. performed the experiments. Lesnikowski A., Theokritoff E., Jagannathan K., Segnon A., Galappaththi E., Vasiliki I., Sitati A., Pentz B., Singh C., Campbell D., Tom Joe E., Mach K., Gichuki L., Cremades R., and Chalastani V. analyzed the data. All authors contributed materials and analysis tools. Thomas A., Lesnikowski A., Theokritoff E., Jagannathan K., Reckien D., Campbell D., and Cremades R. wrote up the paper. All authors were part of the Global Adaptation Mapping Initiative (GAMI). The Global Adaptation Mapping Initiative Team members contributed to the design and implementation of GAMI. A full list of the GAMI Team members can be found at: https://globaladaptation.github.io/.

Open Access This article is licensed under a Creative Commons Attribution 4.0 International License, which permits use, sharing, adaptation, distribution and reproduction in any medium or format, as long as you give appropriate credit to the original author(s) and the source, provide a link to the Creative Commons licence, and indicate if changes were made. The images or other third party material in this article are included in the article's Creative Commons licence, unless indicated otherwise in a credit line to the material. If material is not included in the article's Creative Commons licence and your intended use is not permitted by statutory regulation or exceeds the permitted use, you will need to obtain permission directly from the copyright holder. To view a copy of this licence, visit http://creativecommons.org/licenses/by/4.0/.

\section{References}

Acevedo-Osorio Á, Angarita Leiton A, León Durán MV, Franco Quiroga KL (2017) Sustentabilidad y variabilidad climática: acciones agroecológicas participativas de adaptación y resiliencia socioecológica en la región alto-andina Colombiana. Luna Azul:06-26. https://doi.org/10.4236/ AS.2012.32018

Adger WN, Dessai S, Goulden M, Hulme M, Lorenzoni I, et al (2009) Are there social limits to adaptation to climate change? Clim Chang 93:335-354. https://doi.org/10.1007/s10584-008-9520-z

Ahmed I, Ayeb-Karlsson S, van der Geest K, Huq S, Jordan JC (2019) Climate change, environmental stress and loss of livelihoods can push people towards illegal activities: a case study from coastal Bangladesh. Clim Dev 11:907-917. https://doi.org/10.1080/ 17565529.2019.1586638

Azhoni A, Holman I, Jude S (2017) Adapting water management to climate change: institutional involvement, inter-institutional networks and barriers in India. Glob Environ Chang 44:144-157. https://doi.org/10.1016/j.gloenvcha.2017.04.005

Barnett J, Palutikof JP (2014) The limits to adaptation: a comparative analysis. Applied studies in climate adaptation, pp 231-240

Barnett J, Evans LS, Gross C, Kiem AS, Kingsford RT et al (2015) From barriers to limits to climate change adaptation: path dependency and the speed of change. Ecol Soc:20. https://doi.org/10.5751/ES07698-200305

Bauer K (2013) Are preventive and coping measures enough to avoid loss and damage from flooding in Udayapur district, Nepal? Int J Glob Warm 5:433. https://doi.org/10.1504/IJGW.2013.057292

Berrang-Ford L, Pearce T, Ford JD (2015) Systematic review approaches for climate change adaptation research. Reg Environ Chang 15:755769. https://doi.org/10.1007/s10113-014-0708-7

Berrang-Ford L, Lesnikowski A, Fischer PA, Siders AR, Mach KJ et al (2020) The Global Adaptation Mapping Initiative (GAMI): Part 1 Introduction and overview of methods. Res Sq 7. https://doi.org/10. 21203/rs.3.pex-1240/v1

Berrang-Ford L, Siders AR, Lesnikowski A, Fischer A, Callaghan MW et al (n.d.) A systematic global stocktake of evidence on human adaptation to climate change. Nat Clim Chang. https://doi.org/10. 21203/rs.3.rs-100873/v1

Bhave AG, Conway D, Dessai S, Stainforth DA (2016) Barriers and opportunities for robust decision making approaches to support climate change adaptation in the developing world. Clim Risk Manag 14:1-10. https://doi.org/10.1016/j.crm.2016.09.004 
Biesbroek GR, Termeer CJAM, Klostermann JEM, Kabat P (2014) Analytical lenses on barriers in the governance of climate change adaptation. Mitig Adapt Strateg Glob Chang 19:1011-1032. https:// doi.org/10.1007/s11027-013-9457-z

Bowen KJ, Ebi KL (2015) Governing the health risks of climate change: towards multi-sector responses. Curr Opin Environ Sustain 12:80 85. https://doi.org/10.1016/j.cosust.2014.12.001

Callaghan MW, Minx JC, Forster PM (2020) A topography of climate change research. Nat Clim Chang 10:118-123. https://doi.org/10. 1038/s41558-019-0684-5

Chanza N (2018) Limits to climate change adaptation in Zimbabwe: insights, experiences and lessons. Limits to Climate Change Adaptation. Springer, In, pp 109-127

Dow K, Berkhout F, Preston BL, Klein RJT, Midgley G et al (2013a) Limits to adaptation. Nat Clim Chang 3:305-307. https://doi.org/10. 1038/nclimate 1847

Dow K, Berkhout F, Preston BL (2013b) Limits to adaptation to climate change: a risk approach. Curr Opin Environ Sustain 5:384-391. https://doi.org/10.1016/j.cosust.2013.07.005

Du S, Scussolini P, Ward PJ, Zhang M, Wen J et al (2020) Hard or soft flood adaptation? Advantages of a hybrid strategy for Shanghai. Glob Environ Chang 61:102037. https://doi.org/10.1016/j. gloenvcha.2020.102037

Egbinola CN, Olaniran HD, Amanambu AC (2017) Flood management in cities of developing countries: the example of Ibadan, Nigeria. J Flood Risk Manag 10:546-554. https://doi.org/10.1111/jfr3.12157

Eisenack K, Moser SC, Hoffmann E, Klein RJT, Oberlack C et al (2014) Explaining and overcoming barriers to climate change adaptation. Nat Clim Chang 4:867-872. https://doi.org/10.1038/nclimate2350

Ferdous MR, Wesselink A, Brandimarte L, Slager K, Zwarteveen M, et al (2019) The costs of living with floods in the Jamuna floodplain in Bangladesh. Water 11:1238. https://doi.org/10.3390/w11061238

Filho WL, Nalau J (2018) Limits to Climate Change Adaptation. Springer

Fischer AP, Callaghan M, Nielsen M, Haddaway N (2020) The Global Adaptation Mapping Initiative (GAMI): Part 2 - Screening protocol. https://assets.researchsquare.com/files/pex-1241/v1/cad227747112-46d0-8dc6-a49ecd1e04a5.pdf

GAMI (2021) Publications assessed for Global Adaptation Mapping Initiative. https://doi.org/10.5281/zenodo.4836470

Gawith D, Hodge I (2018) Moving beyond description to explore the empirics of adaptation constraints. Ecol Indic 95:907-916. https:// doi.org/10.1016/j.ecolind.2018.08.022

Gerlicz A, Méndez VE, Conner D, Baker D, Christel D (2019) Use and perceptions of alternative economic activities among smallholder coffee farmers in Huehuetenango and El Quiché departments in Guatemala. Agroecol Sustain Food Syst 43:310-328. https://doi. org/10.1080/21683565.2018.1532480

Gilfillan D (2018) Governance limits to adaptation in Cambodia's health sector. In: Limits to climate change adaptation. Springer, Cham, pp 25-39

Greenough KM (2018) Pastoralists shifting strategies and perceptions of risk: post-crisis recovery in Damergou, Niger. Limits to Climate Change Adaptation. Springer, In, pp 129-142

Haddaway NR, Callaghan MW, Collins AM, Lamb WF, Minx JC et al (2020) On the use of computer-assistance to facilitate systematic mapping. Campbell Syst Rev 16. https://doi.org/10.1002/cl2.1129

Harvey CA, Rakotobe ZL, Rao NS, Dave R, Razafimahatratra H, et al (2014) Extreme vulnerability of smallholder farmers to agricultural risks and climate change in Madagascar. Philos Trans R Soc B Biol Sci 369:20130089. https://doi.org/10.1098/rstb.2013.0089

Hetz K (2018) Political limits to climate change adaptation practices: insights from the Johannesburg case. Limits to Climate Change Adaptation. Springer, In, pp 143-158

Hinkel J, Aerts JCJH, Brown S, Jiménez JA, Lincke D, et al (2018) The ability of societies to adapt to twenty-first-century sea-level rise. Nat Clim Chang 8:570-578. https://doi.org/10.1038/s41558-018-0176-Z
IPCC (2018) Summary for Policymakers. In: Global warming of $1.5^{\circ} \mathrm{C}$. In: An IPCC Special Report on the impacts of global warming of $1.5^{\circ} \mathrm{C}$ above pre-industrial levels and related global greenhouse gas emission pathways, in the context of strengthening the global response to the threat of climate change. World Meteorological Organization, Geneva, Switzerland

IPCC (2019) Summary for Policymakers. In: Gruber Canada S, Guinder $\mathrm{V}$, Hallberg R et al (eds) IPCC special report on the ocean and cryosphere in a changing climate. Hamish Pritchard

Jacobi J (2016) Agroforestry in Bolivia: opportunities and challenges in the context of food security and food sovereignty. Environ Conserv 43:307-316. https://doi.org/10.1017/S0376892916000138

Jamero ML, Onuki M, Esteban M, Tan N (2018) Community-based adaptation in low-lying islands in the Philippines: challenges and lessons learned. Reg Environ Chang 18:2249-2260. https://doi. org/10.1007/s10113-018-1332-8

Jezeer RE, Verweij PA, Boot RGA, Junginger M, Santos MJ (2019) Influence of livelihood assets, experienced shocks and perceived risks on smallholder coffee farming practices in Peru. J Environ Manag 242: 496-506. https://doi.org/10.1016/j.jenvman.2019.04.101

Karapinar B, Özertan G (2020) Yield implications of date and cultivar adaptation to wheat phenological shifts: a survey of farmers in Turkey. Clim Chang 158:453-472. https://doi.org/10.1007/ s10584-019-02532-4

Karlsson M, Hovelsrud GK (2015) Local collective action: adaptation to coastal erosion in the Monkey River Village, Belize. Glob Environ Chang 32:96-107. https://doi.org/10.1016/j.gloenvcha.2015.03.002

Klein RJT, Midgley GF, Preston BL, Alam M, Berkhout FGH, et al (2015) Adaptation opportunities, constraints, and limits. In: Climate change 2014 impacts, adaptation and vulnerability. Part A: Global and Sectoral Aspects. Contribution of Working Group II to the Fifth Assessment Report of the Intergovernmental Panel on Climate Change. Cambridge University Press, pp 899-944

Lamb WF, Creutzig F, Callaghan MW, Minx JC (2019) Learning about urban climate solutions from case studies. Nat Clim Chang 9:279287. https://doi.org/10.1038/s41558-019-0440-x

Lesnikowski A, Berrang-Ford L, Siders AR, Haddaway N, Biesbroek R, et al (2020) The Global Adaptation Mapping Initiative (GAMI): Part 3 - Coding protocol. https://protocolexchange.researchsquare.com/ article/pex-1242/v1

McNamara KE, Westoby R, Smithers SG (2017) Identification of limits and barriers to climate change adaptation: case study of two islands in Torres Strait, Australia. Geogr Res 55:438-455. https://doi.org/ 10.1111/1745-5871.12242

Mechler R, Singh C, Ebi K, Djalante R, Thomas A, et al (2020) Loss and damage and limits to adaptation: recent IPCC insights and implications for climate science and policy. Sustain Sci 15:1245-1251. https://doi.org/10.1007/s11625-020-00807-9

Millner A, Dietz S (2011) Adaptation to climate change and economic growth in developing countries. SSRN Electron J. https://doi.org/10. 2139/ssrn.1935349

Nalau J, Becken S, Mackey B (2018) Ecosystem-based adaptation: a review of the constraints. Environ Sci Pol 89:357-364. https://doi. org/10.1016/j.envsci.2018.08.014

Olhoff A, Skylar B, Daniel P (2015) The adaptation finance gap update with insights from the INDCs

Ologeh IO, Akarakiri JB, Adesina FA (2018) Constraints and limits to climate change adaptation efforts in Nigeria. Limits to Climate Change Adaptation. Springer, In, pp 159-174

Otoara Ha'apio M, Wairiu M, Gonzalez R, Morrison K (2018) Transformation of rural communities: lessons from a local selfinitiative for building resilience in the Solomon Islands. Local Environ 23:352-365. https://doi.org/10.1080/13549839.2017.1420640

Owen G (2020) What makes climate change adaptation effective? A systematic review of the literature. Glob Environ Chang 62: 102071. https://doi.org/10.1016/j.gloenvcha.2020.102071 
Partey ST, Zougmoré RB, Ouédraogo M, Campbell BM (2018) Developing climate-smart agriculture to face climate variability in West Africa: challenges and lessons learnt. J Clean Prod 187:285295. https://doi.org/10.1016/j.jclepro.2018.03.199

Pasaribu SM, Sudiyanto A (2016) Agricultural risk management: lesson learned from the application of rice crop insurance in Indonesia. In: Climate change policies and challenges in Indonesia. Springer Japan, Tokyo, pp 305-322

Pelling M, O'Brien K, Matyas D (2015) Adaptation and transformation. Clim Chang 133:113-127. https://doi.org/10.1007/s10584-014-1303-0

Pritchard B, Thielemans R (2014) 'Rising Waters Don't Lift All Boats': a sustainable livelihood analysis of recursive cycles of vulnerability and maladaptation to flood risk in rural Bihar, India. Aust Geogr 45: 325-339. https://doi.org/10.1080/00049182.2014.930001

Robinson S (2018) Adapting to climate change at the national level in Caribbean small island developing states. Isl Stud J 13:79-100. https://doi.org/10.24043/isj.59

Robinson S (2020) Climate change adaptation in SIDS: a systematic review of the literature pre and post the IPCC Fifth Assessment Report. WIREs Clim Chang 11. https://doi.org/10.1002/wcc.653

Sandholz S, Lange W, Nehren U (2018) Governing green change: ecosystem-based measures for reducing landslide risk in Rio de Janeiro. Int J Disaster Risk Reduct 32:75-86. https://doi.org/10. 1016/j.ijdrr.2018.01.020

Seddon N, Chausson A, Berry P, Girardin CAJ, Smith A et al (2020) Understanding the value and limits of nature-based solutions to climate change and other global challenges. Philos Trans R Soc B Biol Sci 375:20190120. https://doi.org/10.1098/rstb.2019.0120

Shackleton S, Ziervogel G, Sallu S, Gill T, Tschakert P (2015) Why is socially-just climate change adaptation in sub-Saharan Africa so challenging? A review of barriers identified from empirical cases. Wiley Interdiscip Rev Clim Chang 6:321-344. https://doi.org/10.1002/wcc.335

Siders AR (2020) GAMI Intercoder Reliability \& Reconciliation. Zenodo https://zenodo.org/record/4010763\#.YKaL8y8RrOQ. Accessed 20 May 2021

Singh C, Deshpande T, Basu R (2017) How do we assess vulnerability to climate change in India? A systematic review of literature. Reg
Environ Chang 17:527-538. https://doi.org/10.1007/s10113-0161043-y

Sud R, Mishra A, Varma N, Bhadwal S (2015) Adaptation policy and practice in densely populated glacier-fed river basins of South Asia: a systematic review. Reg Environ Chang 15:825-836. https://doi. org/10.1007/s10113-014-0711-z

Team R (2019) R: a language and environment for statistical computing. R Found. Stat. Comput, Vienna, Austria https://www.r-project.org. Accessed 20 May 2021

Thomas A, Shooya O, Rokitzki M, Bertrand M, Lissner T (2019) Climate change adaptation planning in practice: insights from the Caribbean. Reg Environ Chang 19:2013-2025. https://doi.org/10.1007/s10113019-01540-5

Thomas A, Serdeczny O, Pringle P (2020) Loss and damage research for the global stocktake. Nat Clim Chang 10:700. https://doi.org/10. 1038/s41558-020-0807-z

Van Ginkel KCH, Botzen WJW, Haasnoot M, Bachner G, Steininger $\mathrm{KW}$ et al (2020) Climate change induced socio-economic tipping points: review and stakeholder consultation for policy relevant research. Environ Res Lett:15. https://doi.org/10.1088/1748-9326/ ab6395

van Valkengoed AM, Steg L (2019) Meta-analyses of factors motivating climate change adaptation behaviour. Nat Clim Chang 9:158-163. https://doi.org/10.1038/s41558-018-0371-y

Vojinovic Z, Keerakamolchai W, Weesakul S, Pudar R, Medina N et al (2016) Combining ecosystem services with cost-benefit analysis for selection of green and grey infrastructure for flood protection in a cultural setting. Environments 4:3. https://doi.org/10.3390/ environments 4010003

Warner BP (2016) Understanding actor-centered adaptation limits in smallholder agriculture in the Central American dry tropics. Agric Hum Values 33:785-797. https://doi.org/10.1007/s10460-0159661-4

Publisher's note Springer Nature remains neutral with regard to jurisdictional claims in published maps and institutional affiliations.

\title{
Affiliations
}

\author{
Adelle Thomas ${ }^{1,2}$ (1) Emily Theokritoff ${ }^{2,3} \cdot$ Alexandra Lesnikowski $^{4} \cdot$ Diana Reckien $^{5} \cdot$ Kripa Jagannathan $^{6,7}$. \\ Roger Cremades $^{8,9}$. Donovan Campbell ${ }^{10}$ • Elphin Tom Joe ${ }^{11}$ • Asha Sitati ${ }^{12}$. Chandni Singh ${ }^{13}$. Alcade C. Segnon ${ }^{14,15}$. \\ Brian Pentz ${ }^{16}$. Justice Issah Musah-Surugu ${ }^{17}$. Cristina A. Mullin ${ }^{18} \cdot$ Katharine J. Mach $^{19} \cdot$ Leah Gichuki $^{20}$. \\ Eranga Galappaththi ${ }^{21,22}$ • Vasiliki I. Chalastani ${ }^{23}$ • Idowu Ajibade ${ }^{24} \cdot$ Raquel Ruiz-Diaz $^{25}$ • Caitlin Grady ${ }^{26}$. \\ Matthias Garschagen ${ }^{27}$ • James Ford ${ }^{28}$ - Kathryn Bowen ${ }^{29}$. Global Adaptation Mapping Initiative Team
}

Emily Theokritoff

Emily.theokritoff@climateanalytics.org

Alexandra Lesnikowski

Alexandra.lesnikowski@concordia.ca

Diana Reckien

Dianareckien@gmail.com

Kripa Jagannathan

Kripajagen@berkeley.edu

Roger Cremades

Roger.cremades@wur.nl

Donovan Campbell

Donovan.campbell@uwimona.edu.jm
Elphin Tom Joe

Elphin.tom@gmail.com

Asha Sitati

Sitatiasha@gmail.com

Chandni Singh

Csingh@iihs.ac.in

Alcade C. Segnon

Alcadese@gmail.com

Brian Pentz

Brian.pentz@mail.utoronto.ca

Justice Issah Musah-Surugu

Musah123@gmail.com 
Cristina A. Mullin

Cristina.mullin@uconn.edu

Katharine J. Mach

Kmach@miami.edu

Leah Gichuki

1.gichuki@cgiar.org

Eranga Galappaththi

Eranga.research@gmail.com

Vasiliki I. Chalastani

Vanesachala@hotmail.com

Idowu Ajibade

Jajibade@pdx.edu

University of The Bahamas, 1 University Drive, Nassau, Bahamas

2 Climate Analytics, Berlin, Germany

3 Geography Department \& IRI THESys, Humboldt University of Berlin, Berlin, Germany

4 Department of Geography, Planning \& Environment, Concordia University, Montreal, Canada

5 University of Twente, Enschede, The Netherlands

6 Earth and Environmental Sciences Area, Lawrence Berkeley National Lab, Berkeley, CA, USA

7 School for Environment and Sustainability, University of Michigan, Ann Arbor, MI, USA

8 Wageningen University and Research, Wageningen, The Netherlands

9 Climate Service Center Germany (GERICS), Helmholtz-Zentrum Geesthacht, Hamburg, Germany

10 University of the West Indies, Kingston, Jamaica

11 World Resources Institute, New Delhi, India

12 United Nations office for Disaster Risk Reduction (UNDRR), Geneva, Switzerland

13 School of Environment and Sustainability, Indian Institute for Human Settlements, Bangalore City Campus,

Bengaluru, Karnataka, India

14 Faculty of Agronomic Sciences, University of Abomey-Calavi, 01, BP 526 Cotonou, Benin

15 CGIAR Research Program on Climate Change, Agriculture and Food Security (CCAFS), International Crops Research Institute for the Semi-Arid Tropics (ICRISAT), BP 320 Bamako, Mali
Raquel Ruiz-Diaz

Raquel.ruiz103@gmail.com

Caitlin Grady

Cgrady@psu.edu

Matthias Garschagen

m.garschagen@lmu.de

James Ford

j.ford2@leeds.ac.uk

Kathryn Bowen

Kathrynjbowen@gmail.com

16 Department of Physical and Environmental Sciences, University of Toronto Scarborough, 1265 Military Trail, Scarborough, ON M1C 1A4, Canada

17 United Nations University, Bonn, Germany

18 Department of Civil \& Environmental Engineering, University of Connecticut, 261 Glenbrook Road, Unit 3037, Storrs, CT 062693037, USA

19 Rosenstiel School of Marine and Atmospheric Science, University of Miami, Miami, FL, USA

20 Sustainable Livestock Systems, International Livestock Research Institute, Nairobi, Kenya

21 Department of Geography, McGill University, Montreal, Canada

22 Institute of Integrative Biology and Systems, Laval University, Quebec City, Canada

23 Laboratory of Harbor Works, Department of Water Resources and Environmental Engineering, School of Civil Engineering, National Technical University of Athens (NTUA), 15780 Zografou, Greece

24 Department of Geography, Portland State University, Portland, USA

25 Future Oceans Lab, CIM-Universidade de Vigo, Vigo, Spain

26 Penn State University, State College, USA

27 Ludwig-Maximilians-University, Munich, Germany

28 Priestley International Centre for Climate, University of Leeds, Leeds, England

29 Fenner School of Environment and Society, Australian National University, Institute for Advanced Sustainability Studies, Potsdam, Germany 